\title{
Abcc6 deficiency in mice leads to altered $A B C$ transporter gene expression in metabolic active tissues
}

\author{
Bettina Ibold', Isabel Faust', Janina Tiemann'1, Theo G. M. F. Gorgels ${ }^{2,3}$, Arthur A. B. Bergen ${ }^{3,4}$, \\ Cornelius Knabbe ${ }^{1}$ and Doris Hendig ${ }^{1 *}$ (D)
}

\begin{abstract}
Background: ATP-binding cassette (ABC) transporters are involved in a huge range of physiological processes. Mutations in the ABCC6 gene cause pseudoxanthoma elasticum, a metabolic disease with progressive soft tissue calcification.

Methods: The aim of the present study was to analyze gene expression levels of selected $A B C$ transporters associated with cholesterol homeostasis in metabolic active tissues, such as the liver, kidney and white adipose tissue (WAT) of $\mathrm{Abcc6}^{-1-}$ mice from an early and late disease stage (six-month-old and 12-month-old mice).

Results: The strongest regulation of $A B C$ transporter genes was observed in the liver tissue of six-month-old $A b c c 6^{-1}$ mice. Here, we found a significant increase of mRNA expression levels of phospholipid, bile salt and cholesterol/sterol transporters Abcb1b, Abcb11, Abcg1, Abcg5 and Abcg8. Abcd2 mRNA expression was increased by 3.2-fold in the liver tissue. We observed strong upregulation of Abca3 and Abca1 mRNA expression up to 3.3-fold in kidney and WAT, and a 2-fold increase of Abca9 mRNA in the WAT of six-month-old Abcc6 knockout mice. Gene expression levels of $A b c b 1 b$ and $A b c g 1$ remained increased in the liver tissue after an age-related disease progression, while we observed lower mRNA expression of Abca3 and Abca9 in the kidney and WAT of 12-monthold $\mathrm{Abcc6}^{-1-}$ mice.

Conclusions: These data support previous findings that Abcc6 deficiency leads to an altered gene expression of other $A B C$ transporters depending on the status of disease progression. The increased expression of fatty acid, bile salt and cholesterol/sterol transporters may be linked to an altered cholesterol and lipoprotein metabolism due to a loss of Abcc6 function.
\end{abstract}

Keywords: Abcc6, Pseudoxanthoma elasticum, Gene expression, ATP-binding cassette transporters, Mice

\section{Background}

Eukaryotic members of the ATP-binding cassette (ABC) superfamily mediate the export of a wide range of substrates and have, therefore, a functional importance in various physiological processes. These transporter proteins use ATP hydrolysis to move the respective substrate against their concentration gradient. The $\mathrm{ABC}$ transporters are grouped into seven subfamilies depending on

\footnotetext{
* Correspondence: dhendig@hdz-nrw.de

${ }^{1}$ Institut für Laboratoriums- und Transfusionsmedizin, Herz- und Diabeteszentrum Nordrhein-Westfalen, Universitätsklinik der Ruhr-Universität Bochum, Georgstraße 11, D-32545 Bad Oeynhausen, Germany Full list of author information is available at the end of the article
}

structural similarities and conserved sequence motifs. There is a high sequence homology between ABC transporters of mice and man (summarized in [1]). The ABC transporters are highly variable expressed in different tissues. High transporter expression was found in tissues involved in secretory, reproductive and metabolic functions, such as the liver and kidney [2]. Twenty-two of the 48 human $\mathrm{ABC}$ transporters have been implicated in causing monogenetic diseases, such as Tangier disease (gene: $A B C A 1$ ) and Dubin-Johnson syndrome (gene: $A B C C 2)$ [1]. Mutation analyses demonstrated that alterations of $A B C C 6$ gene sequence cause pseudoxanthoma elasticum (PXE; OMIM 264800) [3, 4], an autosomal-recessive

(C) The Author(s). 2019 Open Access This article is distributed under the terms of the Creative Commons Attribution 4.0 International License (http://creativecommons.org/licenses/by/4.0/), which permits unrestricted use, distribution, and 
disease, which is characterized by progressive calcification of connective tissue and manifests in early adolescence. Patients with PXE suffer from skin lesions and ocular manifestations which are associated with spontaneous subretinal neovascularization and hemorrhage. Mineralization of the internal elastic lamina of blood vessels can lead to cardiovascular complications [5]. The level of $A B C C 6$ expression is high in liver and kidney, and much lower or absent in the tissues affected. Recent studies suggested that ABCC6 acts in cellular and systemic pyrophosphate homeostasis although the physiological/endogenous substrates remain unknown [6, 7]. Abcc6 knockout $\left(A b c c 6^{--}\right)$mice develop a PXE-like phenotype and are, therefore, a suitable model for studying the genesis of PXE. Ectopic mineralization of blood vessels first occurs in six-month-old $A b c c 6^{-1-}$ mice in many tissues and progresses with age [8].

In this study, we have examined the expression profile of selected $\mathrm{ABC}$ transporter genes associated with cholesterol homeostasis [9-11] in $A b c c 6^{-1-}$ mice compared to wild type (WT) mice, because there are several indications that PXE is linked to an alteration of cholesterol metabolism accompanied by altered $\mathrm{ABC}$ transporter gene expression $[8,12,13]$. We analyzed gene expression profiles in tissues from metabolic active sites, such as the liver, kidney and white adipose tissue (WAT) [2, 14] from 6- and 12-month-old mice as these ages in mice recapitulate age at disease onset and progressed disease manifestation in PXE patients.

\section{Materials and methods}

\section{Animals}

All animal preparations comply with law on animal welfare of Germany used for scientific purposes. Therefore, an ethical approval is not required. Mice were killed solely for the use of their organs or tissues without prior burden. The $A b c c 6^{-/-}$mice were generated on a hybrid background of C57BL/6 and 129/Ola and backcrossed to C57BL/6 [8]. Mice were housed in the central animal facility of Bielefeld University (Germany) and kept with water and food (normal chow) ad libitum. In the present study, we used $A b c c 6(+/+)$ littermates and pure C57BL/ 6 mice as WT control mice. Mice (males and females), aged 6 months \pm 2 weeks and 12 months \pm 4 weeks, were anesthetized, intraperitoneal with $0.65 \mathrm{mg}$ ketamine, $0.02 \mathrm{mg}$ acepromazine and $0.13 \mathrm{mg}$ xylazine per $10 \mathrm{~g}$ bodyweight and sacrificed by cervical dislocation. After opening the thorax, the right ventricle of the heart was cut for liver perfusion via the hepatic portal vein with phosphate-buffered saline buffer (PBS). The other tissues were only washed in PBS. Liver, kidney and visceral WAT (gonadal) were collected, frozen immediately in liquid $\mathrm{N}_{2}$ and stored at $-80^{\circ} \mathrm{C}$ until use.
RNA extraction from tissue and CDNA synthesis

Total RNAs were extracted from $100 \mathrm{mg}$ liver, kidney and visceral WAT (gonadal) using QIAzol reagent (Qiagen, Hilden, Germany), followed by a purification using RNeasy Mini protocol (Qiagen, Hilden, Germany). Total RNA was treated with DNase I (Macherey-Nagel ${ }^{\mathrm{Tw}}$, Bottrop, Germany) on mini-columns to eliminate genomic DNA. The RNA quantification was assessed by using the NanoDrop 2000 spectrophotometer (Thermo Fisher, Schwerte, Germany) and RNA quality was determined using the Agilent RNA 6000 Nano Kit (Agilent Technologies, Ratingen, Germany), according to the manufacturer's instructions.

First-strand cDNA was synthesized from $1 \mu \mathrm{g}$ of total RNA for each reaction using the SuperScript II Reverse Transcriptase Kit (Thermo Fisher, Schwerte, Germany), according to the manufacturer's instructions. The cDNA was diluted 1:5 or 1:10 with water, depending on the target gene, and stored at $-20^{\circ} \mathrm{C}$ prior to quantitative real-time PCR (qRT-PCR).

\section{Quantitative real-time PCR}

The qRT-PCR was performed on a LightCycler480 (Roche, Mannheim, Germany) using Lightcycler480 MasterCycler SYBR $^{\circ}$ Green (Roche, Mannheim, Germany) to assess the mRNA expression levels of target and reference genes. All intron-spanning primers used for qRT-PCR analysis were designed with Clone Manager Suite 7 (Scientific \& Educational Software), synthesized by Biomers (Ulm, Germany) and are listed in the Additional file 1: Table S1. The PCR thermal cycling conditions contained an initial incubation of $5 \mathrm{~min}$ at $95^{\circ} \mathrm{C}$, followed by 45 cycles of $10 \mathrm{~s}$ degradation at $95^{\circ} \mathrm{C}$, primer-specific annealing for $15 \mathrm{~s}$ at 65 or $59^{\circ} \mathrm{C}$, and $20 \mathrm{~s}$ elongation and detection of the amplicon at $72^{\circ} \mathrm{C}$. Finally, a melting curve analysis of the amplicon was performed. Each cDNA sample was run in technical triplicates. Water was used as a negative control for each primer pair. The relative amount of target mRNA in each sample was calculated using the $\Delta \Delta \mathrm{Ct}$ method, as previously described [15]. Relative mRNA expression levels were corrected by PCR efficiency and the reference genes normalization factor, by normalizing target mRNA Ct values to those of glyceraldehyde-3-phosphate dehydrogenase (Gapdh), hypoxanthine phosphor-ribosyltransferase 1 ( Hprt) and beta-2 microglobulin $(\beta 2 m)$ (6-month-old mice) or Gapdh, Hprt and eukaryotic translation initiation factor 3 subunit A (Eif3a) (12-month-old mice). A cutoff for no detectable mRNA expression was set to a Ct value of 35 .

\section{Statistical analysis}

Data are presented in arbitrary units as means with corresponding standard error (SEM). Graphic data processing and statistical analysis were performed with GraphPad Prism 5 (GraphPad Software, Inc.), using Student's t-tests 
for two group comparisons and the non-parametric Mann-Whitney U test for data which are not Gaussian distributed. The Shapiro-Wilk test was used to determine whether data are normally distributed or not. Significance was accepted at $p \leq 0.05$ (two-tailed).

\section{Results}

The mRNA expression profiles were compared between $A b c c 6^{-1-}$ mice and age-matched WT mice to examine the effects of Abcc6 deficiency on gene expression levels of other $\mathrm{ABC}$ transporters. We determined the relative gene expression of selected $A B C$ subfamily genes (out of subfamilies a, b, c, d and g) in the liver, kidney and visceral WAT (gonadal) of 6- and 12-month-old Abcc6 $6^{-/}$ and WT mice by qRT-PCR.

\section{$A B C$ transporter gene expression in the liver, kidney and white adipose tissue of 6-month-old $\mathrm{Abcc6}^{-/-}$mice}

Alterations of mRNA expression of $\mathrm{ABC}$ transporters were most pronounced in the liver tissue of 6-month-old $A b c c 6^{-/-}$mice compared to WT mice (Fig. 1a). $A b c c 6^{-/-}$ mice showed an $A b c a 9$ mRNA level increase of $70 \%$. The relative mRNA expression of $A b c b 1 b$ and $A b c b 11$ were 1.8, respectively, 1.5 times higher in $A b c c 6^{-1-}$ mice. The hepatic transcript levels of transporters of the Abcg subfamily were significantly higher in $A b c c 6^{-/-}$mice relative to WT mice. In comparison to WT mice, relative gene expression of $A b c g 1$ was 2-fold, that of $A b c g 5$ was 1.5 -fold and that of $A b c g 8$ was 1.9-fold increased in Abcc6-deficient mice. The mRNA levels of $A b c d 2$ were also significantly upregulated (3.2-fold) in $A b c c 6^{-1-}$ mice.

Absence of functional Abcc6 also affected the mRNA expression of $\mathrm{ABC}$ transporter genes in the kidney and WAT of 6-month-old mice. However, relative gene expression of the $A b c a 3$ transporter was significantly increased (2.2-fold) in kidney tissue and in the WAT (3.3-fold) of $\mathrm{Abcc6}^{-1-}$ mice compared to age-matched WT mice (Fig. 1b, c). Figure 1b shows that the relative mRNA expression of Abcal (2.2-fold) and Abcc1 (1.7-fold) were significantly increased in kidney tissue of 6-month-old $A b c c 6^{-/}$mice. We also revealed a significantly higher level of mRNA of the $A b c a 1$ gene (3-fold) and the Abca9 gene (2-fold) in the WAT of Abcc6-deficient mice relative to WT mice (Fig. 1c). Relative mRNA expression levels of the other $\mathrm{ABC}$ transporter genes analyzed did not significantly change between Abcc6-deficient and WT mice.

$A B C$ transporter gene expression in the liver, kidney and white adipose tissue of 12-month-old $\mathrm{Abcc6}^{-/-}$mice

We found that the mRNA expression levels of members of the ABC transporter family a and c (Abca1, Abca3, $A b c a 9, A b c c 1$ and $A b c c 2)$ in the liver tissue of 12-month-old mice were almost comparable to those found in WT mice (Fig. 2a). Post hoc analysis revealed that the Abca6 mRNA down-regulation (0.8-fold) was significant in Abcc6-deficient mice compared to WT mice. Additionally, a statistically insignificant increase in $A b c b 1 b$ expression (1.7-fold) in the liver of $A b c c 6^{-/-}$mice was detected. Hepatic Abcd1 mRNA levels were decreased by $26 \%$ in $\mathrm{Abcc}^{-1-}$ mice in comparison to WT mice. However, we identified an mRNA level increase of all Abcg transporter family member genes (Abcg1, $A b c g 5$ and $A b c g 8)$ measured in the liver tissue of $A b c c 6^{-1-}$ mice. $A b c g 1$ mRNA expression was significantly upregulated (1.8-fold) in $A b c c 6^{-1-}$ mice.

We found significantly lower mRNA expression levels of Abca3 (0.6-fold) in the kidney tissue of 12-month-old Abcc6-deficient mice in comparison to WT mice (Fig. 2b). No significant difference in the gene expression of $A b c a 1$ and $A b c c 1$ was observed.

Gene expression of almost all selected ABC transporters in the WAT of 12-month-old mice was lower in $A b c c 6^{-1-}$ mice (Fig. 2c). The mRNA expression levels of $A b c a 9$ and $A b c d 1$ (0.8-fold each) were significantly lower in the WAT of Abcc6-deficient mice compared to WT mice.

\section{Discussion}

Recent studies demonstrated that patients with DubinJohnson syndrome and $A b c c 2$ knockout rats expressed the $A b c c 3$ gene at a higher level in comparison to WT rats [16]. Compensatory gene expression of $A b c d 2$ was also found in $A b c d 1^{-/-}$mice [17]. In the case of Abcc6 deficiency, Li et al. observed a compensatory, $\sim 6.5$-fold increase of Abca4 gene expression in the liver of 1-month-old Abcc6-deficient mice, but not in kidney and eyes [18]. We showed in our previous study that a loss of ABCC6 function in human dermal fibroblasts results in a compensatory upregulated expression of several $\mathrm{ABC}$ transporters, such as $A B C A 6$ and $A B C A$ 9, whereas $A B C A 3$ was decreased [13]. PXE is described as a systemic disease [19] and ABCC6 expression levels are at their highest in metabolically active tissues, such as liver and kidney[20]. Consequently, we expected strong compensatory changes in the expression profiles of $A B C$ transporters in these tissues.

We observed in the liver tissue of 6-month-old $A b c c 6^{-1-}$ mice that mRNA levels of $A b c d 2$ and the cholesterol transporter gene $A b c g 1$ as well as mRNA levels of phospholipid, bile salt and cholesterol/sterol transporters $A b c b 1 b, A b c b 11, A b c g 5$ and $A b c g 8$, respectively, were significantly upregulated relative to WT mice. By contrast, analysis of phospholipid, bile salt and sterol transporter gene expression in the kidney and WAT of 6- and 12-month-old $A b c c 6^{-1-}$ mice revealed no differences compared to WT mice.

Gorgels et al. reported that $A b c c 6^{-1-}$ mice developed a $25 \%$ reduction in plasma HDL cholesterol and total 


\section{A liver}

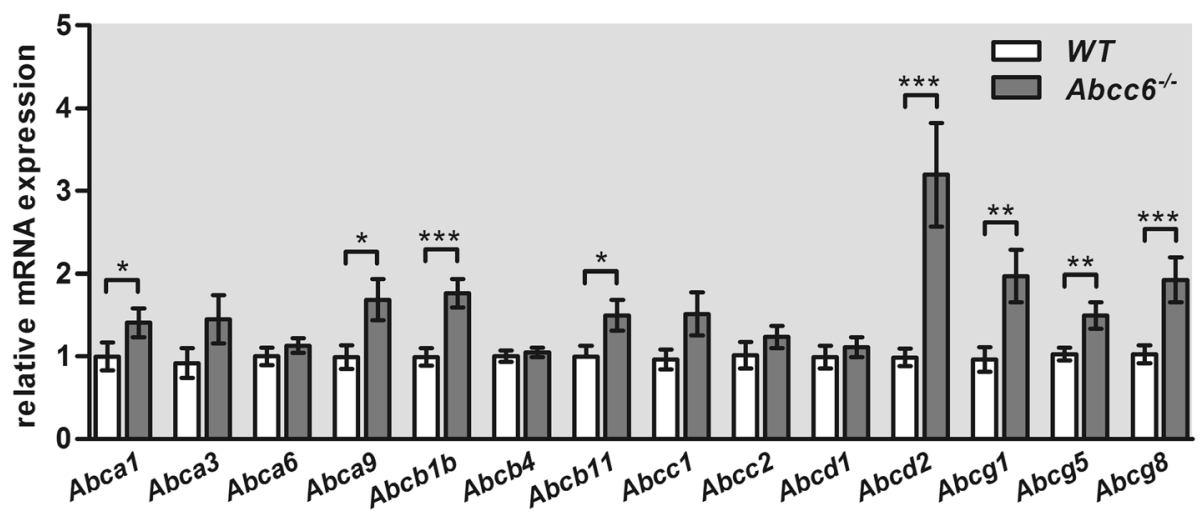

B kidney

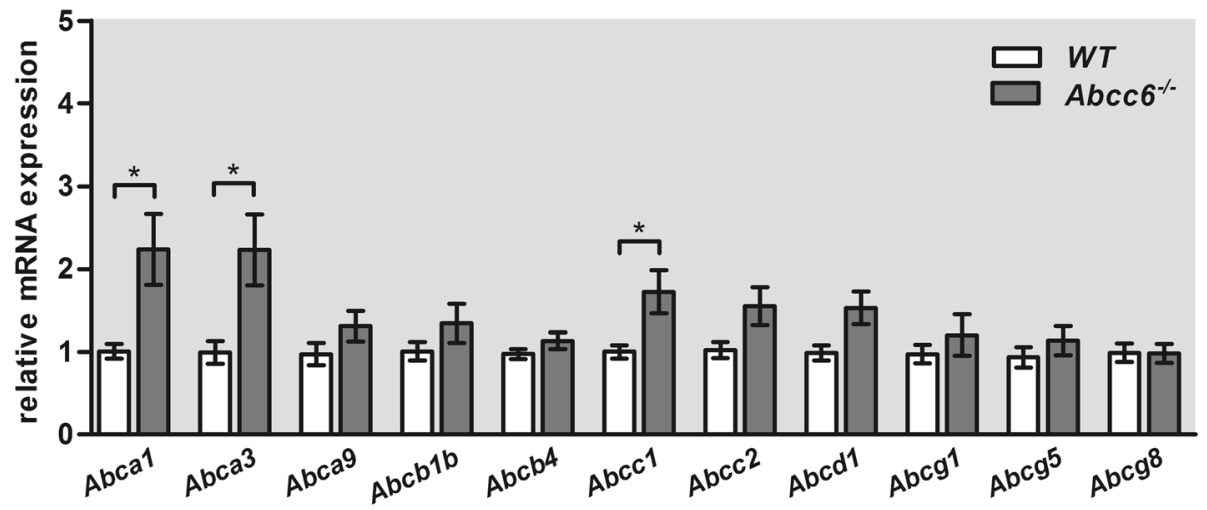

C white adipose tissue

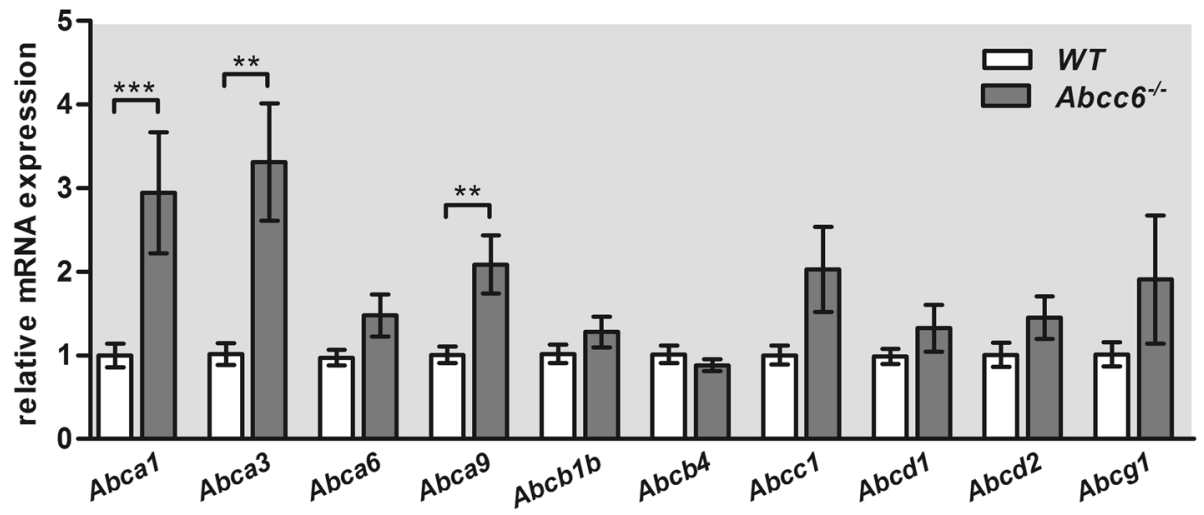

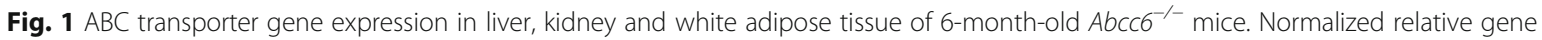
expression level of various ABC transporters in the (a) liver (b) kidney and (c) WAT of 6-month-old \pm 2 weeks male and female WT (liver: $n=25$; kidney: $n=25$; WAT: $n=21$, respectively) and Abcc $^{-1-}$ mice (liver: $n=22$; kidney: $n=23$; WAT: $n=18$, respectively) by qRT-PCR. Relative mRNA expression of $A B C$ transporter members belonging to $a, b, c, d$ and g subfamily. Data are presented as fold change of mean \pm SEM relative to samples of age-matched WT. Statistically significant differences were analyzed using unpaired, two-tailed Student's t-test and are indicated in the following manner: * $p \leq 0.05 ;{ }^{* *} p \leq 0.01 ;{ }^{* * *} p \leq 0.001$

cholesterol [8]. The increase of Abca1 mRNA levels in the liver, kidney and WAT of 6-month-old $A b c c 6^{-1-}$ mice and the upregulation of the hepatic $A b c g 1$ gene expression in 6- and 12-month-old $A b c c 6^{-1-}$ mice may be associated with the change of HDL cholesterol levels. Tangier disease due to ABCA1 deficiency is associated with very low HDL plasma levels and an upregulation of $A B C G 1$ gene expression [21]. The cholesterol depletion 


\section{A liver}

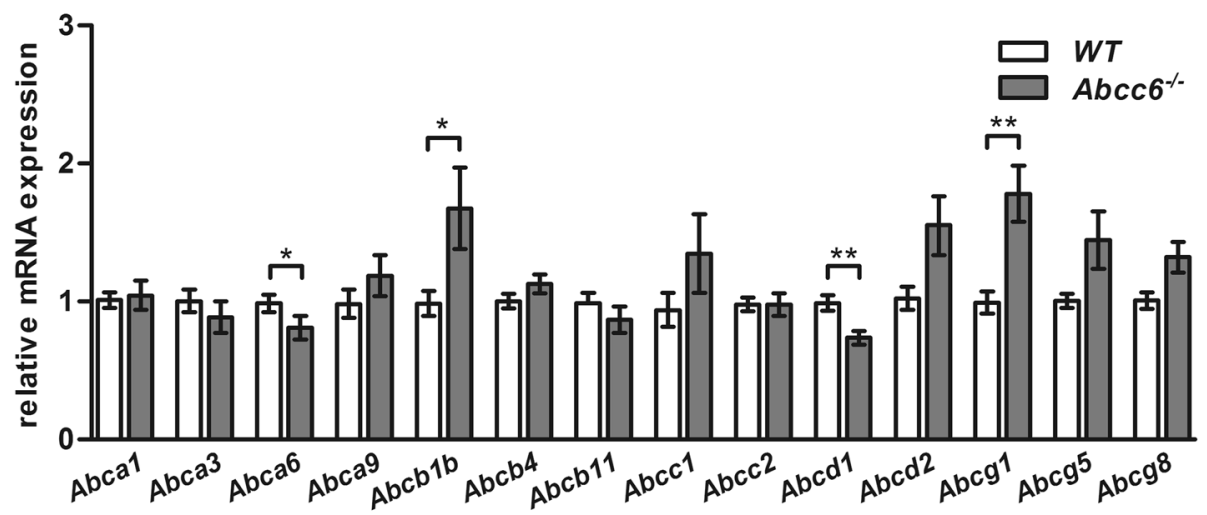

B kidney

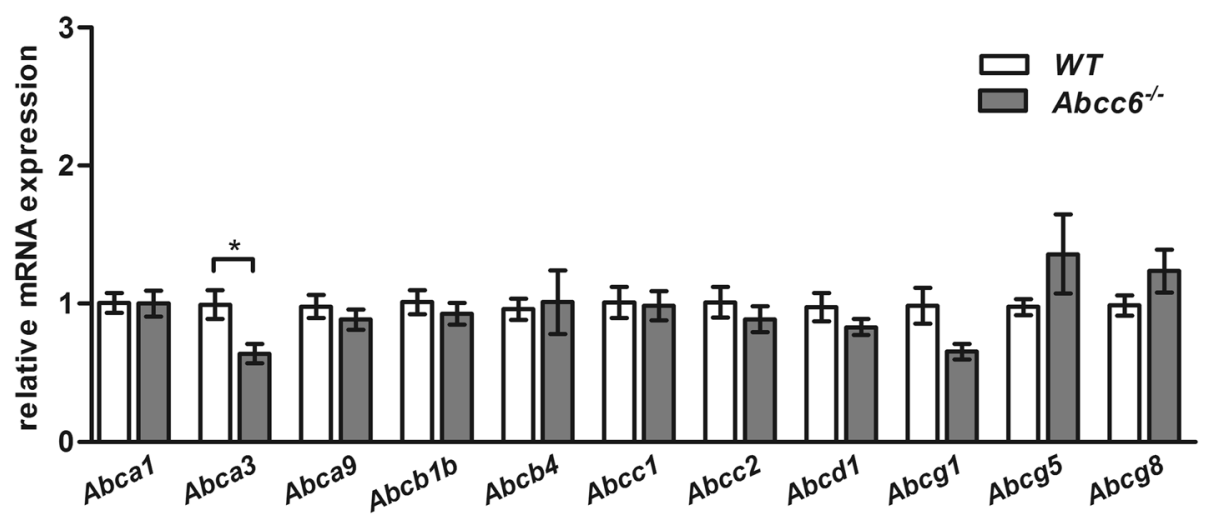

C white adipose tissue

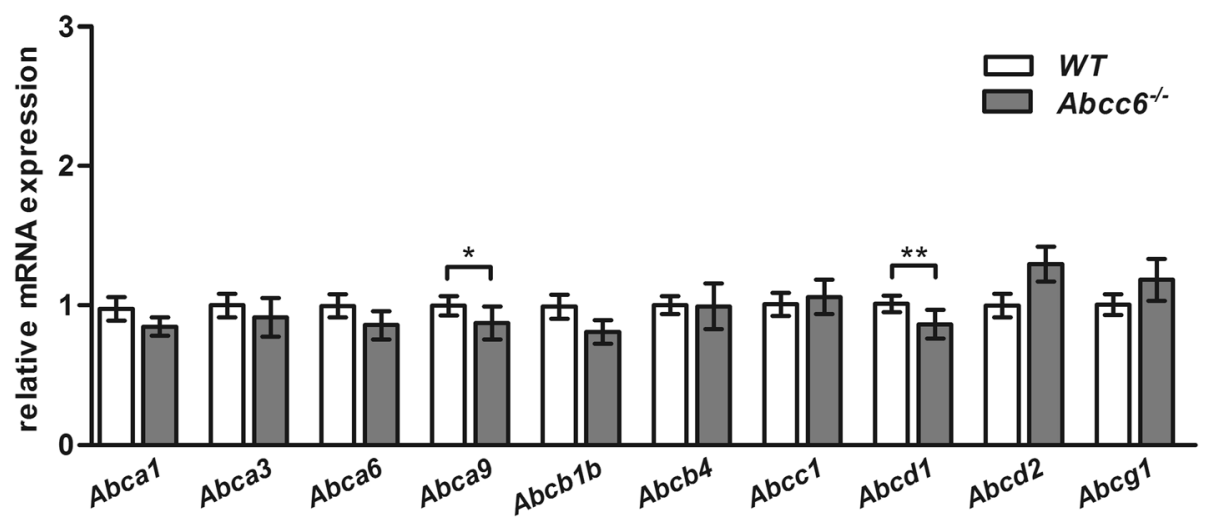

Fig. $2 \mathrm{ABC}$ transporter gene expression in liver, kidney and white adipose tissue of 12 -month-old $A b c c 6^{-1-}$ mice. Normalized relative gene expression level of various ABC transporters in the (a) liver (b) kidney and (c) WAT of 12-month-old \pm 4 weeks male and female WT (liver: $n=37$; kidney: $n=34$; WAT: $n=33$, respectively) and Abcc ${ }^{-1-}$ mice (liver: $n=39$; kidney: $n=42$; WAT: $n=38$, respectively) by qRT-PCR. Relative mRNA expression of $A B C$ transporter members belonging to $a, b, c, d$ and $g$ subfamily. Data are presented as fold change of mean \pm SEM relative to samples of age-matched WT. Statistically significant differences were analyzed using unpaired, two-tailed Student's t-test and are indicated in the following manner: ${ }^{*} p \leq 0.05 ;{ }^{* *} p \leq 0.01 ;{ }^{* *} p \leq 0.001$

proposed might also lead to an induction of $A b c d 2$ mRNA expression, which has already been shown for fibroblasts and monocytes via an activation of transcription factors belonging to the sterol regulatory element-binding protein family [22]. The ABCD transporter family is responsible for the transport of very long-chain fatty acids over the 
peroxisomal membrane, where they are degraded by B-oxidation [23]. Up-regulation of $A b c d 2$ mRNA expression in $A b c c 6^{-1-}$ mice might accompany induced $\beta$-oxidation. We have previously shown increased fatty acid oxidation in skin fibroblasts derived from PXE patients [24].

We showed that gene expression levels of $A b c c 1$ and $A b c c 2$ in the liver of 6- and 12-month-old $A b c c 6^{-1-}$ mice were unaltered compared to WT mice. This observation is in accordance with a previous study analyzing 1-month-old Abcc6 knockout mice [18].

In addition, other members of Abca subfamily seem to be affected by Abcc6 deficiency [13, 18]. Significant alterations of $A b c a 3$ mRNA levels in the kidney and WAT of 6-month-old and in the kidney of 12-month-old mice were detected. The Abca3 protein is not only highly abundant in lamellar bodies, a storage organelle enriched in mixture phospholipids, neutral lipids, cholesterol and hydrophobic proteins, of the lung, but also detectable in extrapulmonary tissues, such as the kidney and liver [25]. Abca 3 expression is decreased after ischemic reperfusion injury in mouse kidney[26], but the role of Abca3 in lipid distribution of extrapulmonary tissues and organs remains unclear. The Abca9 gene has a very high sequence homology to Abca8 (72\%) [10]. An increase of $A b c a 8$ expression levels is associated with the induction of reverse cholesterol transport mediated by HDL particles [27]. It is possible that changes in Abca9 expression levels in the WAT of 6- and 12-month-old mice reflect aberrations of the HDL metabolism of $A b c c 6^{-/-}$mice.

We decided to analyze two different ages of $A b c c 6^{-/-}$ mice, as PXE is a progressive disorder, and, therefore, expected changes in gene expression profiles. Moreover, 6- and 12-month-old mice are comparable in age to patients at an early and at a late disease stage of PXE disease. It has already been shown that $A B C$ transporter expression profiles depend on disease states [28], which might explain the different mRNA expression profiles of $\mathrm{ABC}$ transporters in tissues from 6- and 12-month-old $A b c c 6^{-/-}$mice.

\section{Conclusions}

In summary, Abcc6 deficiency in mice causes the aberrant gene expression of $\mathrm{ABC}$ transporters involved in cholesterol metabolism. These findings reinforce our hypothesis that ABCC6 has a functional role in lipoprotein and cholesterol homeostasis [12], especially in HDL cholesterol. However, the underlying molecular mechanisms behind these changes remain unknown and must be investigated in future studies. It is noteworthy that protein expression of the investigated genes was not analyzed due to study limitations. Therefore, protein expression may differ from mRNA expression.

\section{Additional file}

Additional file 1: Table S1. Primer sequences used for qPCR (DOCX $25 \mathrm{~kb}$ )

Abbreviations

Abc: ATP-binding cassette; ATP: Adenosine triphosphate;

PXE: Pseudoxanthoma elasticum; WAT: White adipose tissue; WT: Wildtype

\section{Acknowledgements}

We thank Axel Ziesenis for his excellent advice on mouse care and management. We further thank Friedrich Krüger, Christoph Lichtenberg, René Kottkamp and Leonie Schröder for their excellent technical assistance and Philip Saunders for his linguistic advice.

\section{Funding}

This research did not receive any specific grant from funding agencies in the public, commercial, or not-for-profit sectors.

\section{Availability of data and materials}

All data generated or analysed during this study are included in this published article [and its supplementary information files].

\section{Authors' contributions}

$\mathrm{Bl}$ performed experiments, analyzed the data and wrote the manuscript. JT and IF contributed to the data analysis and manuscript revision. TG and $A B$ supported the study and experimental design and revised the manuscript critically. DH and CK initiated the study, designed the experiments, supervised the project and contributed to the writing of the manuscript. All authors read and approved the final manuscript.

Ethics approval and consent to participate

Not applicable

\section{Consent for publication}

Not applicable

\section{Competing interests}

The authors declare that they have no competing interests.

\section{Publisher's Note}

Springer Nature remains neutral with regard to jurisdictional claims in published maps and institutional affiliations.

\section{Author details}

${ }^{1}$ Institut für Laboratoriums- und Transfusionsmedizin, Herz- und Diabeteszentrum Nordrhein-Westfalen, Universitätsklinik der Ruhr-Universität Bochum, Georgstraße 11, D-32545 Bad Oeynhausen, Germany. ${ }^{2}$ University Eye Clinic Maastricht, Maastricht University Medical Center, 6202, AZ, Maastricht, The Netherlands. ${ }^{3}$ Netherlands Institute for Neurosciences (NIN-KNAW), Amsterdam, The Netherlands. ${ }^{4}$ Academic Medical Centre, University of Amsterdam, 1100, DD, Amsterdam, The Netherlands.

Received: 1 October 2018 Accepted: 5 December 2018

Published online: 05 January 2019

\section{References}

1. Dean M: The human ATP-binding cassette (ABC) transporter superfamily. [internet]. Bethesda (MD): National Center for biotechnology information (US); 2002. Available from: https://www.ncbi.nlm.nih.gov/books/NBK3/.

2. Langmann T, Mauerer R, Zahn A, Moehle C, Probst M, Stremmel W, Schmitz G. Real-time reverse transcription-PCR expression profiling of the complete human ATP-binding cassette transporter superfamily in various tissues. Clin Chem. 2003:49:230-8.

3. Bergen AA, Plomp AS, Schuurman EJ, Terry S, Breuning M, Dauwerse $H$, Swart J, Kool M, van Soest S, Baas F. Others: mutations in ABCC6 cause pseudoxanthoma elasticum. Nat Genet. 2000;25:228-31.

4. Le Saux O, Urban Z, Tschuch C, Csiszar K, Bacchelli B, Quaglino D, PasqualiRonchetti I, Pope FM, Richards A, Terry S. Others: mutations in a gene 
encoding an $A B C$ transporter cause pseudoxanthoma elasticum. Nat Genet. 2000;25:223-7.

5. Germain DP. Pseudoxanthoma elasticum. Orphanet J Rare Dis. 2017;12:85.

6. Jansen RS, Duijst S, Mahakena S, Sommer D, Szeri F, Váradi A, Plomp A, Bergen AA, Elferink RPO, Borst P. Others: ABCC6-mediated ATP secretion by the liver is the Main source of the mineralization inhibitor inorganic pyrophosphate in the systemic circulation - brief ReportSignificance. Arterioscler Thromb Vasc Biol. 2014;34:1985-9.

7. Ziegler SG, Ferreira CR, EG MF, Riddle RC, Tomlinson RE, Chew EY, Martin L, Ma C-T, Sergienko E, Pinkerton AB. Others: Ectopic calcification in pseudoxanthoma elasticum responds to inhibition of tissue-nonspecific alkaline phosphatase. Sci Transl Med. 2017;9:eaal1669.

8. Gorgels TGMF, Hu X, Scheffer GL, van der Wal AC, Toonstra J, de Jong PTVM, van Kuppevelt TH, Levelt CN, de Wolf A, Loves WJP, Scheper RJ, Peek R, Bergen AAB. Disruption of Abcc6 in the mouse: novel insight in the pathogenesis of pseudoxanthoma elasticum. Hum Mol Genet. 2005;14: 1763-73.

9. Schmitz G, Kaminski WE, Orsó E. ABC transporters in cellular lipid trafficking. Curr Opin Lipidol. 2000;11:493-501.

10. Piehler A, Kaminski WE, Wenzel JJ, Langmann T, Schmitz G. Molecular structure of a novel cholesterol-responsive a subclass $A B C$ transporter, ABCA9. Biochem Biophys Res Commun. 2002;295:408-16.

11. Dikkers A, de Boer JF, Groen AK, Tietge UJ. Hepatic ABCG5/G8 overexpression substantially increases biliary cholesterol secretion but does not impact in vivo macrophage-to-feces RCT. Atherosclerosis. 2015;243:402-6.

12. Kuzaj P, Kuhn J, Dabisch-Ruthe M, Faust I, Götting C, Knabbe C, Hendig D. ABCC6-a new player in cellular cholesterol and lipoprotein metabolism? Lipids Health Dis. 2014;13:118.

13. Hendig D, Langmann T, Kocken S, Zarbock R, Szliska C, Schmitz G, Kleesiek $K$, Götting $C$. Gene expression profiling of $A B C$ transporters in dermal fibroblasts of pseudoxanthoma elasticum patients identifies new candidates involved in PXE pathogenesis. Lab Investig. 2008;88:1303-15.

14. Kershaw EE, Flier JS. Adipose tissue as an endocrine organ. J Clin Endocrinol Metab. 2004;89:2548-56.

15. Livak KJ, Schmittgen TD. Analysis of relative gene expression data using real-time quantitative PCR and the 2(-Delta Delta C(T)) method. Methods. 2001;25:402-8

16. Kuroda M, Kobayashi Y, Tanaka Y, Itani T, Mifuji R, Araki J, Kaito M, Adachi Y. Increased hepatic and renal expressions of multidrug resistance-associated protein 3 in Eisai hyperbilirubinuria rats. J Gastroenterol Hepatol. 2004;19: $146-53$.

17. Pujol A, Ferrer I, Camps C, Metzger E, Hindelang C, Callizot N, Ruiz M, Pàmpols $T$, Giròs M, Mandel JL. Functional overlap between ABCD1 (ALD) and ABCD2 (ALDR) transporters: a therapeutic target for $\mathrm{X}$ adrenoleukodystrophy. Hum Mol Genet. 2004;13:2997-3006

18. Li Q, Jiang Q, LaRusso J, Klement JF, Sartorelli AC, Belinsky MG, Kruh GD, Uitto J. Targeted ablation of Abcc1 or Abcc3 in Abcc6-/- mice does not modify the ectopic mineralization process. Exp Dermatol. 2007;16:853-9.

19. Uitto J, Pulkkinen L, Ringpfeil F. Molecular genetics of pseudoxanthoma elasticum: a metabolic disorder at the environment-genome interface? Trends Mol Med. 2001;7:13-7.

20. Scheffer GL, Hu X, Pijnenborg AC, Wijnholds J, Bergen AA, Scheper RJ. MRP6 (ABCC6) detection in normal human tissues and tumors. Lab Investig. 2002; 82:515-8.

21. Lorkowski S, Kratz M, Wenner C, Schmidt R, Weitkamp B, Fobker M, Reinhardt J, Rauterberg J, Galinski EA, Cullen P. Expression of the ATPbinding cassette transporter gene ABCG1 (ABC8) in Tangier disease. Biochem Biophys Res Commun. 2001;283:821-30.

22. Weinhofer I, Forss-Petter S, Zigman M, Berger J. Cholesterol regulates ABCD2 expression: implications for the therapy of $X$-linked adrenoleukodystrophy. Hum Mol Genet. 2002;11:2701-8.

23. Linka N, Theodoulou FL: Metabolite transporters of the plant peroxisomal membrane: known and unknown. In Peroxisomes and their Key Role in Cellular Signaling and Metabolism Springer; 2013:169-194.

24. Kuzaj P, Kuhn J, Michalek RD, Karoly ED, Faust I, Dabisch-Ruthe M, Knabbe C, Hendig D. Large-scaled metabolic profiling of human dermal fibroblasts derived from pseudoxanthoma elasticum patients and healthy controls. PLoS One. 2014;9:e108336.

25. Beers MF, Mulugeta $S$. The biology of the $A B C A 3$ lipid transporter in lung health and disease. Cell Tissue Res. 2017:1-13.
26. Huls M, van den Heuvel JJ, Dijkman HB, Russel FG, Masereeuw R. ABC transporter expression profiling after ischemic reperfusion injury in mouse kidney. Kidney Int. 2006;69:2186-93.

27. Trigueros-Motos L, van Capelleveen JC, Torta F, Castaño D, Zhang L-H, Chai EC, Kang M, Dimova LG, Schimmel AW, Tietjen I. Others: ABCA8 regulates cholesterol efflux and high-density lipoprotein cholesterol levels. Arterioscler Thromb Vasc Biol. 2017:37:2147-55.

28. Gu X, Manautou JE. Regulation of hepatic ABCC transporters by xenobiotics and in disease states. Drug Metab Rev. 2010;42:482-538.

\section{Ready to submit your research? Choose BMC and benefit from:}

- fast, convenient online submission

- thorough peer review by experienced researchers in your field

- rapid publication on acceptance

- support for research data, including large and complex data types

- gold Open Access which fosters wider collaboration and increased citations

- maximum visibility for your research: over $100 \mathrm{M}$ website views per year

At BMC, research is always in progress.

Learn more biomedcentral.com/submissions 